\title{
Environmental Tobacco Smoke and Coronary Heart Disease Mortality in the United States-A Meta-Analysis and Critique
}

\author{
James E. Enstrom \\ Jonsson Comprehensive Cancer Center, University of California, Los Angeles, California, USA
}

Geoffrey C. Kabat

New Rochelle, New York, USA

\begin{abstract}
Several major meta-analyses have concluded that exposure to environmental tobacco smoke (ETS) increases the risk of coronary heart disease (CHD) by about $25 \%$ among never smokers. However, these reviews have excluded a large portion of the epidemiologic evidence on questionable grounds and have been inconsistent in the selection of the results that are included. We conducted an updated meta-analysis and critique of the evidence on ETS exposure and its relationship to death from CHD among never smokers. Our focus is on the U.S. cohort studies, which provide the vast majority of the available evidence. ETS exposure is assessed in terms of spousal smoking, self-reported estimates, and personal monitoring. The epidemiologic results are summarized by means of overall relative risks and dose-response relationships. The methodological issues of publication bias, exposure misclassification, and confounding are discussed. Several large studies indicate that spousal smoking history is a valid measure of relative exposure to ETS, particularly for females. Personal monitoring of nonsmokers indicates that their average ETS exposure from a smoking spouse is equivalent in terms of nicotine exposure to smoking less than 0.1 cigarettes per day. When all relevant studies are included in the meta-analysis and results are appropriately combined, current or ever exposure to ETS, as approximated by spousal smoking, is associated with roughly a 5\% increased risk of death from CHD in never smokers. Furthermore, there is no dose-response relationship and no elevated risk associated with the highest level of ETS exposure in males or females. An objective assessment of the available epidemiologic evidence indicates that the association of ETS with CHD death in U.S. never smokers is very weak. Previous assessments appear to have overestimated the strength of the association.
\end{abstract}

It is generally believed that exposure to environmental tobacco smoke (ETS) increases the relative risk of death from coronary heart disease (CHD) among never smokers. The American Heart Association, the California Environmental Protection Agency, and the U.S. Surgeon General have all concluded that

Received 24 June 2005; accepted 20 September 2005.

This analysis has been funded primarily by Philip Morris USA. However, it is based on knowledge about the epidemiology of ETS gained by the authors over the past 25 years, during which time they received extensive research funding from the National Cancer Institute, the American Cancer Society, and other sources. Furthermore, all of the underlying data and methodology used in this article are publicly available and can be independently verified.

Address correspondence to James E. Enstrom, PhD, MPH, Jonsson Comprehensive Cancer Center, University of California, Los Angeles, CA 90095, USA. E-mail: jenstrom@ucla.edu the increase in coronary heart disease risk due to ETS is 30\% (relative risk of 1.30) (Taylor er al., 1992; NCI, 1999; U.S. DHHS, 2001). This relative risk (RR) is based primarily on comparing never smokers married to smokers with never smokers married to never smokers. Meta-analysis has been used to combine the results of observational epidemiological studies on this issue (Bailar, 1999). Three major meta-analyses of about 8 U.S. and 10 non-U.S. epidemiological studies have reported worldwide summary relative risks ( $95 \%$ confidence intervals) of 1.30 (1.22 to 1.38 ), 1.25 (1.17 to 1.32 ), and 1.25 (1.17 to 1.33 ) (Law et al., 1997; He et al.,1999; Thun et al., 1999). The summary relative risk for the U.S. studies has been reported as $1.22(1.13-1.30)$ (Thun et al., 1999).

However, the relationship between ETS and CHD is still controversial, as can be seen from our recent epidemiologic study (Enstrom \& Kabat, 2003a) and the reactions to it (Thun, 2003; Enstrom \& Kabat, 2003b, 2004; Smith, 2003; Ungar \& Bray, 
2005). We believe there are three main reasons for the controversy. First, considering that ETS is much more dilute than actively inhaled smoke, it seems etiologically implausible that ETS could cause a 30\% increase in CHD risk (Bailar, 1999), although arguments to the contrary have been made (Law et al., 1997). Second, the overall strength of the epidemiologic evidence depends greatly on which results from the individual studies are included in a summary meta-analysis (Law et al., 1997; Enstrom \& Kabat, 2003a; LeVois \& Layard, 1995). Third, the importance of the ETS issue to both antismoking activists and to the tobacco industry has made it difficult to arrive at an objective assessment of the evidence on this question (Bayer \& Colgrove, 2002; Kluger, 1996).

We examine the underlying quality and consistency of the U.S. epidemiologic evidence and present a comprehensive meta-analysis. This review is organized into an assessment of ETS exposure data, an extrapolation of ETS risk from active smoking risk, a meta-analysis of the overall and doseresponse results on ETS and CHD, a discussion of methodological issues, and conclusions. We have limited our review to U.S. evidence for a number of reasons: the U.S. data represent the vast majority of the available evidence; this evidence comes almost entirely from cohort studies conducted in fairly similar ways; substantial supplementary information is available on the largest cohorts; and the relationship between ETS exposure and disease in other countries may differ from that in the United States. This article analyzes those findings that are based on and most relevant to the U.S. population.

\section{ASSESSMENTS OF ETS EXPOSURE \\ Spousal Smoking and Self-Reported Exposure}

The relationship between ETS and CHD in the United States has been established largely among several cohorts of never smokers who were born before 1940 and who died of CHD after 1960. The assumption underlying most of these studies is that the spousal smoking history of these never smokers is a valid measure of their relative ETS exposure. In order to demonstrate the validity of this assumption, we show in Table 1 the results of five separate U.S. surveys.

California Cancer Prevention Study. These data pertain to our extended follow-up of the California (CA) subjects in the original American Cancer Society (ACS) Cancer Prevention Study (CPS I) (Enstrom \& Kabat, 2003a). Results show that 1959 spousal smoking was strongly related to self-reported history of total ETS exposure as of 1999 among female never smokers born during 1900-1929. The relationship among male never smokers was positive but weak.

Washington County Study. These data pertain to the subjects enrolled in a private 1963 census of Washington County, Maryland residents (Sandler et al., 1989a). Results show a strong correlation between 1963 spousal smoking and total household smoke exposure score among male and female never smokers mostly born during 1890-1938 (Sandler et al., 1989b).

Kaiser-Permanente Survey. These data pertain to the northern California members of the Kaiser Permanente Health Plan (Friedman et al., 1983). Results show a strong correlation between 1979-80 spousal smoking and self-reported current total ETS exposure (at home and work) among male and female nonsmokers mostly born during 1900-1959.

Nationwide Cancer Prevention Study. These data pertain to the nationwide subjects in the second ACS Cancer Prevention Study (CPS II) (Steenland et al., 1996). Results from a related dissertation show a strong correlation between 1982 spousal smoking and self-reported current ETS exposure at home among female never smokers mostly born during 1910-1939 (Cardenas, 1995).

Missouri Radon Study. These data pertain to the general population controls from the Missouri Radon Study, a large lung cancer case-control study (Brownson et al., 1992). Our analysis of the underlying data (Alavanja, 1995) shows a strong relationship between 1988-90 spousal smoking and self-reported household ETS exposure among female never smokers born during 1900-1929.

All five surveys indicate a clear relationship between spousal smoking and self-reported ETS exposure among never smokers, particularly female never smokers. Furthermore, this relationship exists even though the subjects in these surveys lived the major portion of their lives before smoking bans were first enacted in the 1970s.

\section{Quantitative Measurements of Exposure}

Quantitative ETS exposure data come from studies since the 1970s that have directly measured levels of tobacco smoke, particularly nicotine, in various indoor environments (NCI, 1999; U.S. EPA, 1992; Phillips et al., 1998; Jenkins et al., 1996). Most average concentrations of nicotine range from 0.3 to $30 \mu \mathrm{g} / \mathrm{m}^{3}$. The average concentration in residences with at least 1 smoker ranges from 2 to $10 \mu \mathrm{g} / \mathrm{m}^{3}$, with concentrations in workplaces being similar (NCI, 1999). The most accurate and comprehensive measurements of individual ETS exposure come from personal monitoring of the breathing zone of nonsmokers at home and in the workplace (Phillips et al., 1998; Jenkins et al., 1996). Surveys of nonsmokers in a number of cities in the United Kingdom, Europe, and Australia indicated that average ETS exposure was roughly equivalent to smoking 0.03 cigarettes per day for those living and working with smokers (Phillips et al., 1994, 1998; Phillips \& Bentley, 2001). A large study of nonsmokers in sixteen US cities provided similar estimates of ETS exposure (Jenkins et al., 1996). The home was found to be the greatest source of ETS exposure (Phillips et al., 1994; Jenkins et al.,1996). These estimates indicate that the actual ETS exposure of a never smoker married to a smoker is less than the exposure resulting from smoking 0.1 cigarettes per day. 
TABLE 1

Spousal smoking status versus self-reported ETS exposure among never smokers: Percentage distribution for subjects in five major ETS studies California CPS I never smokers born during 1900-1929 (Enstrom \& Kabat, 2003a, Table 4)

History of regular exposure to cigarette smoke from others in work or daily life as of $1999(\%)$

\begin{tabular}{|c|c|c|c|c|c|}
\hline \multirow{2}{*}{1959 Spousal smoking } & \\
\hline & None & Light & Moderate & Heavy & Total 1999 subjects \\
\hline \multicolumn{6}{|l|}{ Males } \\
\hline Never & 43.5 & 34.5 & 19.7 & 2.3 & 435 \\
\hline Current & 23.1 & 38.5 & 32.4 & 6.0 & 117 \\
\hline \multicolumn{6}{|l|}{ Females } \\
\hline Never & 61.7 & 24.3 & 10.9 & 3.1 & 645 \\
\hline Current: $1-19$ cigs/day & 25.5 & 28.8 & 39.4 & 6.3 & 208 \\
\hline Current: $20-39$ cigs/day & 19.7 & 20.9 & 41.3 & 18.1 & 426 \\
\hline Current: $40+$ cigs/day & 16.2 & 12.5 & 47.5 & 23.8 & 80 \\
\hline
\end{tabular}

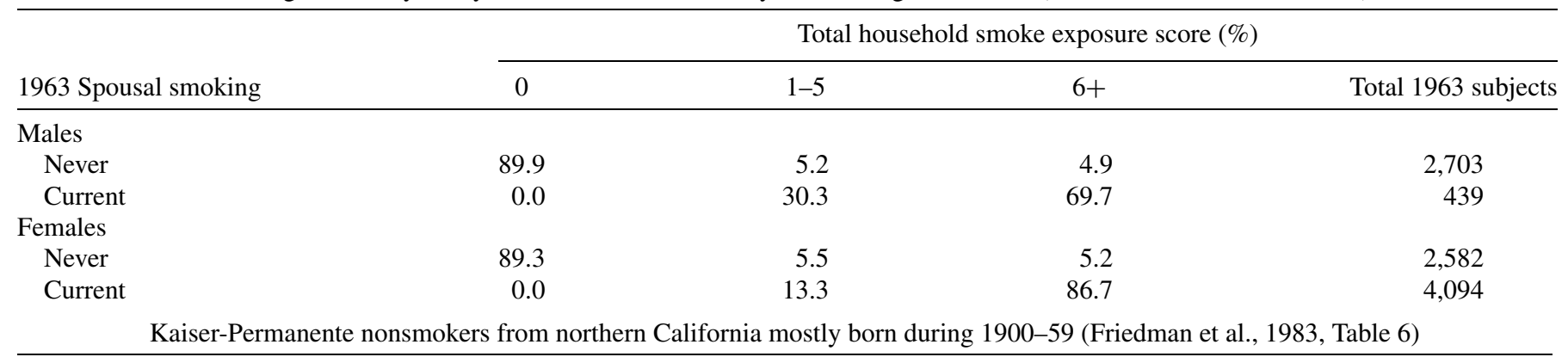

Current number of hours per week of total ETS as of 1979-80 (\%)

\begin{tabular}{|c|c|c|c|c|c|}
\hline \multirow[b]{2}{*}{ 1979-1980 Spousal smoking } & \\
\hline & 0 & $1-9$ & $10-39$ & $40+$ & Total 1979-1980 subjects \\
\hline \multicolumn{6}{|l|}{ Males } \\
\hline Never & 50.8 & 32.3 & 13.8 & 3.1 & 130 \\
\hline \multicolumn{6}{|l|}{ Females } \\
\hline Never & 59.4 & 29.7 & 6.7 & 6.0 & 579 \\
\hline Current & 35.4 & 23.4 & 20.0 & 21.1 & 175 \\
\hline
\end{tabular}

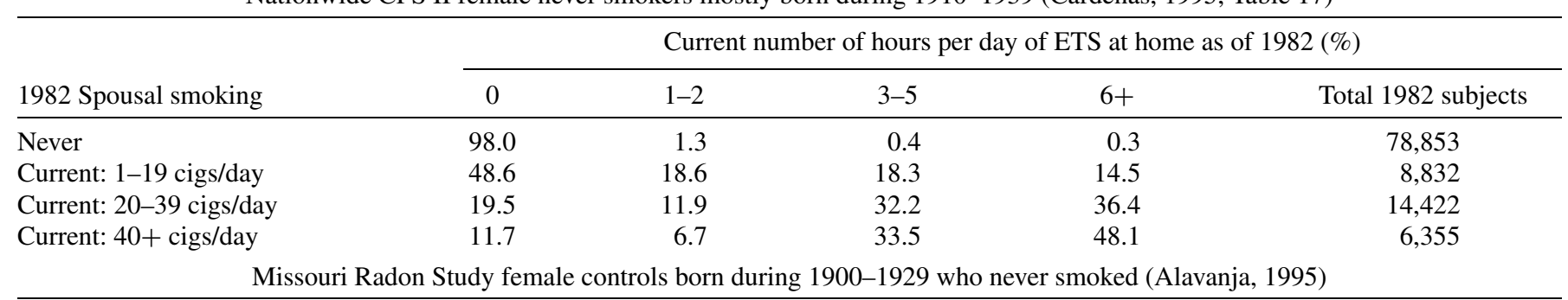

\begin{tabular}{|c|c|c|c|c|c|}
\hline \multirow[b]{2}{*}{$\begin{array}{l}\text { 1988-1990 Spousal/other } \\
\text { smoking history }\end{array}$} & \multicolumn{5}{|c|}{ Average exposure to smoke at home during adult years (\%) } \\
\hline & None & Light & Moderate & Heavy & $\begin{array}{l}\text { Total } 1988-1990 \\
\text { subjects }\end{array}$ \\
\hline None & 61.7 & 37.3 & 1.0 & 0.0 & 292 \\
\hline $\begin{array}{l}\text { 1-19 cigs/day maximum } \\
\text { spousal smoking }\end{array}$ & 0.9 & 85.7 & 12.5 & 0.9 & 112 \\
\hline $\begin{array}{l}40+\text { cigs/day maximum } \\
\text { spousal smoking }\end{array}$ & 0.0 & 24.3 & 46.7 & 29.0 & 107 \\
\hline Other smoking at home & 0.4 & 76.2 & 19.6 & 3.8 & 235 \\
\hline
\end{tabular}


TABLE 2

Dose-response relationship between active smoking and CHD mortality: Relative risk (RR and 95\% CI) of CHD death for current cigarette smokers compared to never smokers

\begin{tabular}{|c|c|c|c|c|c|c|}
\hline & \multicolumn{3}{|c|}{ Males } & \multicolumn{3}{|c|}{ Females } \\
\hline & Subjects & Deaths & $\mathrm{RR}(95 \% \mathrm{CI})$ & Subjects & Deaths & $\mathrm{RR}(95 \% \mathrm{CI})$ \\
\hline & \multicolumn{6}{|c|}{ CPS I cohort ${ }^{a}$} \\
\hline 1959 Active smoking & \multicolumn{3}{|c|}{ 1960-1972 Follow-up } & \multicolumn{3}{|c|}{ 1960-1972 Follow-up } \\
\hline Never & 92,307 & 8193 & 1.00 & 375,649 & 16,458 & 1.00 \\
\hline \multicolumn{7}{|l|}{ Current } \\
\hline 1-9 cigs/day & $\sim 13,506$ & 1186 & 1.25 & $\sim 40,087$ & 772 & 1.07 \\
\hline 10-19 cigs/day & $\sim 31,103$ & 2934 & 1.45 & $\sim 50,037$ & 1189 & 1.48 \\
\hline 20 cigs/day & $\sim 67,864$ & 6068 & 1.58 & $\sim 49,540$ & 1192 & 1.45 \\
\hline 21-39 cigs/day & $\sim 39,848$ & 3143 & 1.57 & $\sim 14,010$ & 310 & 1.81 \\
\hline 40-80 cigs/day & $\sim 22,676$ & 2045 & 1.84 & $\sim 5053$ & 121 & 1.42 \\
\hline Total & 174,997 & 15,376 & 1.53 & 158,727 & 3584 & 1.33 \\
\hline & \multicolumn{6}{|c|}{ CA CPS I cohort ${ }^{b}$} \\
\hline 1959 Active smoking & \multicolumn{3}{|c|}{ 1960-1998 Follow-up } & \multicolumn{3}{|c|}{ 1960-1998 Follow-up } \\
\hline Never & 10,862 & 2561 & 1.00 & 39,216 & 6516 & 1.00 \\
\hline \multicolumn{7}{|l|}{ Current } \\
\hline Occasional & 231 & 48 & $0.84(0.63-1.12)$ & 444 & 57 & $1.06(0.82-1.38)$ \\
\hline 1-9 cigs/day & 1548 & 376 & $1.19(1.07-1.33)$ & 4687 & 590 & $1.13(1.04-1.23)$ \\
\hline 10-19 cigs/day & 3740 & 859 & $1.42(1.31-1.53)$ & 6691 & 855 & $1.43(1.33-1.54)$ \\
\hline 20 cigs/day & 7186 & 1661 & $1.57(1.48-1.68)$ & 6875 & 912 & $1.79(1.66-1.92)$ \\
\hline 21-39 cigs/day & 4789 & 1072 & $1.75(1.63-1.89)$ & 2066 & 254 & $2.04(1.80-2.32)$ \\
\hline 40-80 cigs/day & 2621 & 573 & $1.91(1.74-2.10)$ & 818 & 111 & $2.38(1.97-2.87)$ \\
\hline Total & 19,884 & 4541 & $1.53(1.45-1.61)$ & 21,137 & 2722 & $1.49(1.42-1.56)$ \\
\hline & \multicolumn{6}{|c|}{ CA CPS I cohort ${ }^{b}$} \\
\hline 1972 Active smoking & \multicolumn{3}{|c|}{ 1973-1998 Follow-up } & \multicolumn{3}{|c|}{ 1973-1998 Follow-up } \\
\hline Never & 5983 & 1313 & 1.00 & 21,824 & 3392 & 1.00 \\
\hline \multicolumn{7}{|l|}{ Current } \\
\hline 1-4 cigs/day & 305 & 62 & $1.10(0.85-1.42)$ & 461 & 49 & $1.09(0.82-1.45)$ \\
\hline $5-9 \mathrm{cigs} /$ day & 341 & 75 & $1.35(1.07-1.70)$ & 667 & 75 & $1.19(0.94-1.49)$ \\
\hline $10-19$ cigs/day & 1054 & 253 & $1.68(1.46-1.92)$ & 2135 & 269 & $1.52(1.34-1.72)$ \\
\hline 20 cigs/day & 2156 & 465 & $1.68(1.51-1.87)$ & 3189 & 403 & $1.81(1.63-2.02)$ \\
\hline $21-39$ cigs/day & 1014 & 204 & $1.69(1.45-1.97)$ & 1026 & 118 & $2.04(1.69-2.45)$ \\
\hline $40-80$ cigs/day & 1051 & 208 & $1.95(1.67-2.27)$ & 803 & 103 & $2.52(2.06-3.07)$ \\
\hline Total & 5922 & 1267 & $1.62(1.49-1.75)$ & 8282 & 1017 & $1.64(1.53-1.77)$ \\
\hline
\end{tabular}

${ }^{a}$ Burns et al. (1997).

${ }^{b}$ Enstrom and Kabat (2003a).

\section{ETS EFFECTS EXTRAPOLATED FROM ACTIVE SMOKING DATA}

Table 2 shows there was a strong, positive, long-term doseresponse relation between active cigarette smoking and CHD deaths among the CA CPS I cohort during 1960-1998 and during 1973-1998 (Enstrom \& Kabat, 2003a), as well as among the full CPS I cohort during 1960-1972 (Burns et al., 1997). During 1960-1998 smoking occasional cigarettes resulted in RRs of about 1.0 and smoking 1-9 cigarettes per day (cigs/day) resulted in RRs of about 1.15; during 1960-1972 smoking 1-
9 cigs/day resulted in RRs of about 1.15; and during 1973-1998 smoking 1-4 cigs/day resulted in RRs of about 1.1. By interpolation, the RR associated with smoking $1 \mathrm{cig} / \mathrm{day}$ in this cohort was only about 1.03 and the RR associated with smoking 0.1 cigs/day would not be measurably different from 1.0 . These dose-response relationships are highly relevant to the ETS issue because a large portion of the U.S. epidemiologic evidence comes from the CA CPS I and full CPS I studies, as detailed later. The RR( $1 \mathrm{cig} /$ day) of about 1.03 as constructed above is much lower than the $\mathrm{RR}(1 \mathrm{cig} /$ day $)$ of about 1.4 constructed 
primarily from cohort study results on male subjects during the 1950s (Law et al., 1997; Howard \& Thun, 1999).

\section{META-ANALYSIS OF U.S. COHORT STUDIES}

Most epidemiological studies have found that ETS exposure has a positive, but not statistically significant, relation to CHD. In order to describe an overall summary relationship, these observational results have been combined using meta-analysis methodology (Bailar, 1999; Law et al., 1997; He et al., 1999; Thun et al., 1999). The resulting summary relative risks, which are significantly greater than 1.0, have then been interpreted as evidence of a causal relationship. Following this same approach, we present a new meta-analysis that combines all available results according to more explicit and uniform criteria.

Specifically, we include the results from CA CPS I (Enstrom \& Kabat, 2003a) and CPS I (LeVois \& Layard, 1995), which were not included in three major meta-analyses (Law et al., 1997 He et al., 1999; Thun et al., 1999). These two studies are so large that they comprise the major portion of the U.S. epidemiologic evidence (about $80 \%$ by statistical weight). Both studies were begun by the ACS, but the analyses have been conducted and published independently of the ACS, with research funding from the tobacco industry. The ACS has claimed that the results based on CPS I are flawed and unusable for ETS analyses because all nonsmokers were equally exposed to ETS in the 1950s and 1960s, regardless of spousal smoking status (Thun et al., 1999; Thun, 2003). However, the ACS has produced no evidence to support its claim, which is contradicted by the evidence in Table 1. The ACS has also failed to acknowledge that the results from CA CPS I and CPS I are largely consistent with its own CPS II results (Steenland et al., 1996), as we demonstrate below.

Table 3 shows key characteristics of the nine U.S. cohort studies (Enstrom \& Kabat, 2003a; LeVois \& Layard, 1995; Steenland et al., 1996; Garland et al., 1985; Svendsen et al., 1987; Butler, 1988; Sandler et al., 1989a; Humble et al., 1990; Kawachi et al., 1997), including location, years of follow-up, cohort size, number of CHD deaths by ETS exposure status at entry, primary definition of ETS exposure, and availability of information on exposure misclassification. The relative statistical weight of each cohort is roughly proportional to the total number of CHD deaths and is shown next to the number of deaths. Most studies used spousal smoking to define exposure. However, a couple of studies had information on exposure in the workplace and total household exposure. Age-adjusted RRs have been used wherever possible in order to make the most meaningful comparisons, since different studies have controlled for different covariates. The remaining U.S. evidence on ETS and CHD, two-case-control studies (Layard, 1995; Muscat \& Wynder, 1995), is not included in Table 3 but is discussed later.

The individual relative risks of CHD from all nine U.S. cohort studies are shown in Table 4 for three exposure contrasts: former/never, current/never, and ever/never. Table 5 shows the summary relative risks for groups of studies, calculated with the statistical package STATA, which provides both the fixed effects and random effects models for meta-analysis (Sterne et al., 1995). The meta-analysis formulas for the fixed effects model are shown in Appendix Table 1. Group A comprises the seven studies used in the previously cited meta-analyses, which analyzed only one exposure contrast, exposed/unexposed, and which selected the maximum RR from the exposure contrasts of current/never or ever/never exposure (Law et al., 1997; He et al., 1999; Thun et al., 1999). Group B is the CA CPS I (Enstrom \& Kabat, 2003a) and Group C is the full CPS I (LeVois \& Layard, 1995). About 7\% of the 1960-1972 deaths in CPS I occurred in California and are the same as the 1960-1972 deaths in CA CPS I. However, this minimal overlap of deaths has no measurable effect on the summary RRs.

The Group A RRs highlighted in bold in Table 4 are those used in the Thun et al. (1999) meta-analysis, which yielded the summary RR(exposed/unexposed) of 1.22 for US studies for both sexes. However, by distinguishing between "current/never" and "ever/never" exposure, the summary RR(current/never) was 1.18 and the summary RR(ever/never) was 1.10 for Group A, based on the fixed effects model, as shown in Table 5. When Group B (CA CPS I) or Group C (CPS I) was included, the summary $\mathrm{RR}$ (current/never) was 1.05 and the summary $\mathrm{RR}($ ever/never) was 1.04. If both Group B and Group C were included, the summary RR(current/never) was 1.04 and the summary RR(ever/never) was 1.03 . Thus, inclusion of CA CPS I and/or CPS I yielded summary RRs that were very close to 1.0 and significantly smaller than 1.22.

The summary RRs(current/never) for females were the same for the fixed effects and random effects models, because the individual RRs were homogeneous. This homogeneity can be seen in Table 4, where the 95\% CI for each RR included the summary RR of 1.05 shown in Table 5. Calculations of the summary $\mathrm{RRs}$ (current/never) for females and of the test for heterogeneity, where $p$ equals 0.66, are presented in detail in Appendix Table 2. There were small differences between the fixed effects and random effects models for males, primarily because the CPS I RRs differ from the CPS II RRs. When heterogeneous RRs were combined, the summary RRs and 95\% CIs based on the random effects model were generally somewhat larger than the RRs and 95\% CIs based on the fixed effects model. However, when all three groups and both sexes were combined, the fixed effects and random effects models yielded virtually the same summary RR of 1.04 .

Inclusion of the two U.S. case-control studies (Layard, 1995; Muscat \& Wynder, 1995) would slightly lower the summary RRs for ever/never exposure. The larger U.S. case-control study, based on a national follow-back survey of $4317 \mathrm{CHD}$ deaths during 1986, reported an RR (ever/never) of 0.97 (0.73-1.28) for males and 0.99 (0.84-1.16) for females (Layard, 1995). The smaller U.S. case-control study, based on 272 CHD cases during 1980-1990 from hospitals in four cities, reported an RR (ever/never) of $1.30(0.70-2.40)$ for males and $1.70(0.70-3.70)$ for females (Muscat \& Wynder, 1995).

As explained earlier, the non-U.S. studies have not been included because they are not directly relevant to the relationship 


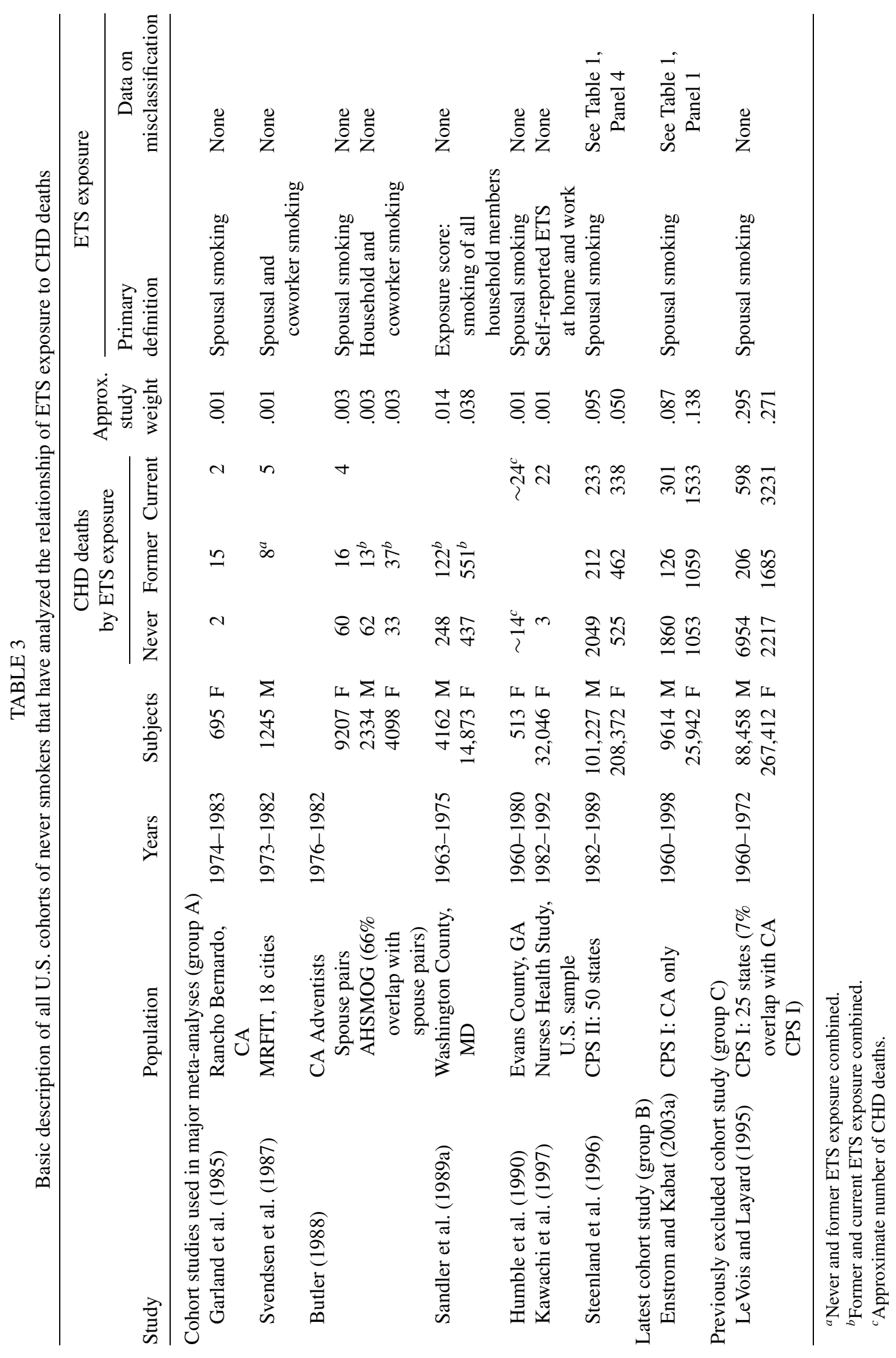


TABLE 4

Overall relationship between ETS exposure and CHD mortality in U.S. cohort studies in groups A, B, and C: Relative risk (RR \& 95\% CI) compares never smokers with ETS exposure (former, current, or ever) to never smokers with no ETS exposure (never)

\begin{tabular}{|c|c|c|c|}
\hline \multirow[b]{2}{*}{ Group and study } & \multicolumn{3}{|c|}{ Relative risk by ETS exposure category } \\
\hline & $\mathrm{RR}($ former/never) & RR(current/never) & $\mathrm{RR}($ ever/never) \\
\hline \multicolumn{4}{|l|}{ Males } \\
\hline A, Svendsen et al. (1987) & & $2.11^{d}(0.69-6.46)^{d}$ & \\
\hline A, Butler (1988)-AHSMOG & & & $0.55^{c, d}(0.31-0.99)^{d}$ \\
\hline A, Sandler et al. (1989a) & & & $1.31^{a} \quad(1.05-1.64)$ \\
\hline A, Steenland et al. (1996) & $0.96^{a}(0.83-1.11)$ & $1.22^{a}(1.07-1.40)$ & $1.09^{a, c}(0.99-1.21)$ \\
\hline B, Enstrom \& Kabat (2003a) & $0.94(0.78-1.12)$ & $0.94 \quad(0.83-1.07)$ & $0.94 \quad(0.85-1.05)$ \\
\hline C, LeVois \& Layard (1995) & $0.95(0.83-1.09)$ & $0.98^{c}(0.90-1.06)$ & $(0.90-1.05)$ \\
\hline \multicolumn{4}{|l|}{ Females } \\
\hline A, Garland et al. (1985) & $3.00(0.8-12.0)^{b}$ & $2.25(0.5-11.0)^{b}$ & $\mathbf{2 . 7 3}^{b}(\mathbf{0 . 7 - 1 1 . 0})^{b}$ \\
\hline A, Butler (1988)-Spouse Pairs & $0.96(0.55-1.66)$ & $1.40(0.51-3.84)$ & $1.05^{a}(0.64-1.70)$ \\
\hline A, Butler (1988)-AHSMOG & & & $1.51^{c} \quad(0.99-2.29)$ \\
\hline A, Sandler et al. (1989a) & & & $1.19^{a}(1.04-1.36)$ \\
\hline A, Humble et al. (1990) & & $1.29(0.79-2.10)$ & \\
\hline A, Kawachi et al. (1997) & & $1.87(0.56-6.20)$ & \\
\hline A, Steenland et al. (1996) & $1.00^{a}(0.88-1.13)$ & $1.10^{a}(0.96-1.27)$ & $1.04^{a, c}(0.95-1.15)$ \\
\hline B, Enstrom \& Kabat (2003a) & $1.02(0.93-1.11)$ & $1.01 \quad(0.93-1.09)$ & $1.01 \quad(0.94-1.08)$ \\
\hline C, LeVois \& Layard (1995) & $0.99(0.93-1.05)$ & $1.05^{c}(1.01-1.09)$ & $(0.98-1.08)$ \\
\hline
\end{tabular}

between ETS and CHD in the United States. Most of the nonU.S. studies report fairly large RRs (on the order of 1.5), but they are primarily case-control studies that provide RRs only for ever/never exposure. The non-U.S. studies, which were done in eight different countries, often did not use the same definition of CHD as the U.S. studies. Inclusion of the non-U.S. results does not materially alter the summary RRs for the U.S. results. The non-U.S. results have been included in other meta-analyses (Law et al., 1997; He et al., 1999; Thun et al., 1999).

The relative risk of CHD as a function of level of spousal smoking is shown in Table 6 for the three largest studies. There is substantial agreement between the results of CA CPS I (Enstrom \& Kabat, 2003a), CPS I (LeVois \& Layard, 1995), and CPS II (Steenland et al., 1996). The meta-analysis summary of these results at each level of exposure shows no RR greater than 1.05 and no upper $95 \%$ CI greater than 1.12. All female RRs and all but one male RR are consistent with 1.00. Furthermore, the female RRs are homogeneous across all studies in Table 6, as they were in Table 4 . The fact that there is no dose-response relationship whatsoever, even among females, is particularly significant since females are more likely to show a relationship than males. This is because historically females have been exposed to more ETS from their spouses than males and to less ETS outside the home than males.
Since inclusion of the CA CPS I and/or the CPS I data has such a strong effect on the outcome of the meta-analysis, it is important to examine the two primary reasons that have been given for excluding these results. First, Thun et al. (1999) and Thun (2003) have argued that CPS I cannot be used to measure the impact of ETS on CHD because of their claim that all never smokers in the CPS I cohort, including those married to never smokers, were equally exposed to ETS during the 1950s and 1960s. We showed in our paper (Enstrom \& Kabat, 2003a) and in Table 1 that a large portion of never smokers reported little or no ETS exposure. Indeed, if this claim of universal ETS exposure were true it would invalidate all of the other U.S. studies because their subjects were also alive during the 1950s and 1960s. Thun et al. (1999) saw fit to include other studies of spousal smoking initiated in the 1960s, such as Sandler et al. (1989a) and Humble et al. (1990). The same standard for inclusion should be applied to all studies.

Law et al. (1997) provide a second reason for excluding the CPS I data. They argue that the CPS I results are incompatible with those of all other studies combined and must therefore be flawed, most likely because the analysis was funded by the tobacco industry. But they offer no specific evidence. As we showed in Table 4, the CPS I RRs are, in fact, compatible with almost all of the RRs of the other studies when examined one 
TABLE 5

Overall relationship between ETS exposure and CHD mortality: Meta-analysis summary of U.S. cohort studies for combinations of groups A, B, and C

\begin{tabular}{|c|c|c|c|c|c|}
\hline \multirow[b]{2}{*}{ Model and group } & \multicolumn{5}{|c|}{ Summary relative risk by ETS exposure category } \\
\hline & $\mathrm{RR}$ (former/never) & $\mathrm{RR}(\mathrm{c}$ & irrent/never) & $\mathrm{RR}($ & ever/never) \\
\hline \multicolumn{6}{|l|}{ Males } \\
\hline Fixed: A & $(0.83-1.11)$ & 1.23 & $(1.08-1.41)$ & $1.11^{a}$ & $(1.01-1.21)$ \\
\hline Random: A & $0.96 \quad(0.83-1.11)$ & 1.23 & $(1.08-1.41)$ & $1.05^{a}$ & $(0.80-1.38)$ \\
\hline Fixed: $A+B$ & $0.95 \quad(0.85-1.07)$ & $1.07^{a}$ & $(0.97-1.17)$ & $1.03^{a}$ & $(0.96-1.11)$ \\
\hline Random: $\mathrm{A}+\mathrm{B}$ & $0.95 \quad(0.85-1.07)$ & $1.11^{a}$ & $(0.86-1.42)$ & $1.03^{a}$ & $(0.86-1.23)$ \\
\hline Fixed: $\mathrm{A}+\mathrm{C}$ & $(0.86-1.05)$ & $1.04^{a}$ & $(0.97-1.12)$ & $1.03^{a}$ & $(0.97-1.09)$ \\
\hline Random: A + C & $0.95 \quad(0.86-1.05)$ & $1.11^{a}$ & $(0.90-1.38)$ & $1.04^{a}$ & $(0.89-1.22)$ \\
\hline Fixed: $\mathrm{A}+\mathrm{B}+\mathrm{C}$ & $0.95 \quad(0.87-1.04)$ & $1.02^{a}$ & $(0.96-1.08)$ & $1.00^{a}$ & $(0.95-1.06)$ \\
\hline Random: $\mathrm{A}+\mathrm{B}+\mathrm{C}$ & $0.95 \quad(0.87-1.04)$ & $1.05^{a}$ & $(0.91-1.21)$ & $1.02^{a}$ & $(0.91-1.14)$ \\
\hline \multicolumn{6}{|l|}{ Females } \\
\hline Fixed: A & $1.01 \quad(0.89-1.14)$ & 1.13 & $(0.99-1.29)$ & 1.10 & $(1.02-1.19)$ \\
\hline Random: A & $1.01 \quad(0.89-1.14)$ & 1.13 & $(0.99-1.29)$ & 1.14 & $(1.00-1.30)$ \\
\hline Fixed: $\mathrm{A}+\mathrm{B}$ & $1.02(0.95-1.09)$ & 1.04 & $(0.97-1.11)$ & 1.05 & $(1.00-1.11)$ \\
\hline Random: $\mathrm{A}+\mathrm{B}$ & $1.02(0.95-1.09)$ & 1.04 & $(0.97-1.11)$ & 1.09 & $(0.99-1.19)$ \\
\hline Fixed: A + C & $0.99 \quad(0.94-1.05)$ & 1.06 & $(1.01-1.10)$ & 1.05 & $(1.01-1.09)$ \\
\hline Random: $\mathrm{A}+\mathrm{C}$ & $0.99 \quad(0.94-1.05)$ & 1.06 & $(1.01-1.10)$ & 1.08 & $(1.00-1.18)$ \\
\hline Fixed: $\mathrm{A}+\mathrm{B}+\mathrm{C}$ & $1.00 \quad(0.96-1.05)$ & 1.05 & $(1.01-1.08)$ & 1.04 & $(1.00-1.08)$ \\
\hline Random: $\mathrm{A}+\mathrm{B}+\mathrm{C}$ & $1.00 \quad(0.96-1.05)$ & 1.05 & $(1.01-1.08)$ & 1.06 & $(1.00-1.12)$ \\
\hline \multicolumn{6}{|l|}{ Both sexes } \\
\hline Fixed: A & $0.99 \quad(0.90-1.08)$ & 1.18 & $(1.07-1.29)$ & $1.10^{a}$ & $(1.04-1.17)$ \\
\hline Random: A & $0.99 \quad(0.90-1.08)$ & 1.18 & $(1.07-1.29)$ & $1.13^{a}$ & $(1.01-1.25)$ \\
\hline Fixed: $\mathrm{A}+\mathrm{B}$ & $1.00 \quad(0.94-1.06)$ & 1.05 & $(0.99-1.11)$ & $1.04^{a}$ & $(1.00-1.09)$ \\
\hline Random: $\mathrm{A}+\mathrm{B}$ & $1.00 \quad(0.94-1.06)$ & 1.08 & $(0.98-1.18)$ & $1.07^{a}$ & $(0.99-1.16)$ \\
\hline Fixed: $\mathrm{A}+\mathrm{C}$ & $0.98 \quad(0.94-1.02)$ & 1.05 & $(1.02-1.09)$ & $1.04^{a}$ & $(1.01-1.08)$ \\
\hline Random: A + C & $0.98 \quad(0.94-1.02)$ & 1.08 & $(1.00-1.15)$ & $1.07^{a}$ & $(1.00-1.15)$ \\
\hline Fixed: $\mathrm{A}+\mathrm{B}+\mathrm{C}$ & $0.99 \quad(0.95-1.03)$ & 1.04 & $(1.01-1.07)$ & $1.03^{a}$ & $(1.00-1.06)$ \\
\hline Random: $\mathrm{A}+\mathrm{B}+\mathrm{C}$ & $0.99 \quad(0.95-1.03)$ & 1.04 & $(0.99-1.10)$ & $1.04^{a}$ & $(0.99-1.10)$ \\
\hline Fixed: (Thun et al., 1999) & \multicolumn{5}{|c|}{$\mathrm{RR}($ exposed/not exposed $)=\mathbf{1 . 2 2}(\mathbf{1 . 1 3}-\mathbf{1 . 3 0})$} \\
\hline
\end{tabular}

Note. Summary relative risk (RR \& 95\% CI) compares never smokers with ETS exposure (former, current, or ever) to never smokers with no ETS exposure (never). Results from fixed effects and random effects models are shown.

${ }^{a}$ Heterogeneity among the RRs combined in the summary RR $(p<.05)$.

at a time. In the present highly polarized climate, tobacco industry funding has been used to automatically discredit results beyond any appeal. We believe that there is no justification for the exclusion of CPS I because the reasons given by Thun et al. (1999) and Law et al. (1997) simply do not stand up to scrutiny.

\section{METHODOLOGICAL ISSUES Publication Bias}

Three major phenomena operating in ETS-CHD epidemiology suggest the existence of a publication bias against null findings. First is the unusual behavior of the ACS regarding CPS I. While claiming that the two published analyses of CPS
I (Enstrom \& Kabat, 2003a; LeVois \& Layard, 1995) should be ignored because they are supposedly flawed (Thun et al., 1999; Thun, 2003), the ACS has failed to substantiate these claims and has refused to publish its own analysis of the CPS I data (Enstrom \& Kabat, 2003b). This certainly suggests that ACS does not want to confirm the existing null CPS I results. Second is the fact that none of the U.S. investigators has updated their initial positive, but inconclusive, findings, with additional mortality follow-up or refinement of the ETS exposure measurements in order to produce more definitive findings. Third are the ad hominem attacks by antismoking activists on reputable scientists like us (Enstrom \& Kabat, 2003b, 2004) and the largescale campaign to silence our scientific findings (Ungar \& Bray, 
TABLE 6

Dose-response relationship between ETS exposure and CHD mortality: Relative risk of spousal smoking related to CHD deaths among never smokers in CA CPS I, CPS II, and CPS I and summary RR of the three studies

\begin{tabular}{|c|c|c|c|c|}
\hline Spousal smoking & $\begin{array}{l}\text { 1960-1998 CA CPS I } \\
\text { age-adjusted } \\
\text { RR (95\% CI), } \\
\text { Enstrom and Kabat } \\
\text { (2003a, extracted from } \\
\text { Tables } 7 \text { and } 8) \\
\text { (group B) }\end{array}$ & $\begin{array}{l}\text { 1982-1989 CPS II } \\
\text { fully-adjusted } \\
\text { RR (95\% CI), } \\
\text { Steenland et al. } \\
\text { (1996, extracted } \\
\text { from Table 2) } \\
\text { (from group A) }\end{array}$ & $\begin{array}{l}\text { 1960-1972 CPS I } \\
\text { age-adjusted } \\
\text { RR (95\% CI), } \\
\text { LeVois and Layard } \\
\text { (1995, extracted } \\
\text { from Table 4) } \\
\text { (group C) }\end{array}$ & $\begin{array}{c}\text { Summary } \\
\text { "age-adjusted" } \\
\text { RR (95\% CI), } \\
\text { Enstrom and Kabat (2003a), } \\
\text { Steenland et al. (1996), } \\
\text { and LeVois and Layard } \\
\text { (1995) }\end{array}$ \\
\hline \multicolumn{5}{|l|}{ Males } \\
\hline Never & 1.00 & 1.00 & 1.00 & 1.00 \\
\hline Former & $(0.78-1.12)$ & $(0.83-1.11)$ & $(0.83-1.09)$ & $(0.87-1.04)$ \\
\hline \multicolumn{5}{|l|}{ Current } \\
\hline 1-19 cigs/day & $0.91^{a}(0.78-1.06)$ & 1.33 (1.09-1.61) & $(0.89-1.09)$ & $(0.94-1.10)$ \\
\hline $20 \mathrm{cigs} /$ day & $0.92 \quad(0.74-1.15)$ & $1.17(0.92-1.48)$ & & \\
\hline Former & $(0.93-1.11)$ & $1.00(0.88-1.13)$ & $(0.93-1.05)$ & $(0.95-1.05)$ \\
\hline \multicolumn{5}{|l|}{ Current } \\
\hline 1-19 cigs/day & $1.07^{a}(0.96-1.19)$ & $1.15(0.90-1.48)$ & $(0.97-1.12)$ & $(0.99-1.12)$ \\
\hline 20 cigs/day & $1.04 \quad(0.92-1.16)$ & $1.07(0.83-1.40)$ & & \\
\hline 20-39 cigs/day & & & $(0.98-1.15)$ & $1.04(0.98-1.10)$ \\
\hline $21-39 \mathrm{cigs} /$ day & $(0.80-1.12)$ & $0.99(0.67-1.47)$ & & \\
\hline $40+$ cigs/day & $(0.65-1.06)$ & $1.04(0.67-1.61)$ & $0.95 \quad(0.78-1.15)$ & $0.92 \quad(0.79-1.06)$ \\
\hline
\end{tabular}

${ }^{a} \mathrm{RR}$ was based on combining other RRs.

2005). Such attacks certainly serve as a strong disincentive for other researchers to publish null findings or even enter this area of epidemiology.

\section{Misclassification of Exposure and Smoking Status}

Misclassification of ETS exposure status occurs because of exposure to sources other than the spouse and because of changes in spousal smoking over time. Nondifferential misclassification of exposure status generally produces a measured relative risk that is closer to 1.0 than the true relative risk, but this is not always the case (Jurek et al., 2005). Thus, initial spousal smoking status is not a perfect measure of ETS exposure, but the results in Table 1 indicate that it is a valid indicator of relative ETS exposure, particularly for females. Furthermore, Table 6 shows that female never smokers married to current smokers of $40+$ cigs/day in the CA CPS I, CPS I, and CPS II cohorts had no increased risk of CHD death, since their summary RR was 0.92 (0.79-1.06). This would be the subgroup subject to the highest ETS exposure due to spousal smoking and the minimum exposure misclassification due to workplace ETS.

Misclassification of active smokers as never smokers could produce relative risks that are biased upward. However, the CA
CPS I study indicates that the 1959 never smokers reported very little smoking history as of 1999. The few percent of "never smokers" with a smoking history tended to be the ones with the highest levels of spousal smoking, but the amount of their active smoking was small (Enstrom \& Kabat, 2003a). Because of the low relative risk for CHD due to current active smoking $(\leq 2.5)$, this small level of misclassification has only a negligible effect on the $\mathrm{CHD}$ relative risks.

\section{Confounding}

Confounding could conceivably explain some portion of the excess risk attributed to ETS exposure. Particularly when an RR is between 1.0 and 2.0 the distorting effects due to confounding in an observational study need to be considered. The cohort studies have addressed a range of confounding factors including age, health status, education, body mass index, diet, and alcohol consumption, and other CHD risk factors. However, none of the cohort studies has controlled for the confounding effect of widowhood, an established risk factor for mortality that is more likely to be experienced by those married to smokers, as we demonstrated in CA CPS I (Enstrom \& Kabat, 2003a). The effect of widowhood may partially explain the large RRs in some 
studies. In general, those confounding variables that have been controlled for do not cause any consistent change in the RRs (Law et al., 1997; Thun et al., 1999).

\section{CONCLUSIONS}

The present meta-analysis indicates how sensitive the summary RRs are to the inclusion of CA CPS I and/or CPS I results and to use of a consistent definition of exposure. Our results indicate that the ETS-CHD association is considerably weaker than that reported in previous meta-analyses. We believe the primary reason our meta-analysis shows a very weak relationship between ETS and CHD deaths is because actual levels of ETS exposure are too low to cause many deaths. Because the whole issue of the health effects of ETS exposure has been highly politicized, there has been a pattern of selectively using the available evidence to make the strongest case against ETS. However, science requires that all of the evidence be evaluated critically and even-handedly. The uncertainty of the epidemiologic evidence on passive smoking and CHD needs to be acknowledged. Public health practitioners should focus on the strong evidence regarding the adverse effects of active smoking on CHD. The case against active smoking is not helped by exaggerating the evidence on passive smoking.

\section{REFERENCES}

Alavanja, M. C. 1995. Missouri Radon Study. Response from NCI to Freedom of Information (FOA) request to NCI, NIH.

Bailar, J. C. 1999. Passive smoking, coronary heart disease, and metaanalysis. N. Engl. J. Med. 340:958-959 http://content.nejm.org/ cgi/content/full/340/12/958.

Bayer, R., and Colgrove, J. 2002. Science, politics, and ideology in the campaign against environmental tobacco smoke. Am. J. Public Health 92:949-954.

Brownson, R. C., Alavanja, M. C., Hock, E. T., and Loy, T. S. 1992. Passive smoking and lung cancer in nonsmoking women. Am. J. Public Health 82:1525-1530.

Burns, D. M., Shanks, T. G., Choi, W., Thun, M. J., Heath, C. W. Jr., and Garfinkel, L. 1997. The American Cancer Society Cancer Prevention Study I: 12-Year followup of 1 million men and women. In Smoking and Tobacco Control Monograph 8, NIH Publication No. 97-4213, pp. 113-304 (Tables 11 and 13).

Butler, T. L. 1988. The relationship of passive smoking to various health outcomes among Seventh-day Adventists in California. Doctoral dissertation, University of California, Los Angeles.

Cardenas, V. M. 1995. Environmental tobacco smoke and lung cancer mortality in the American Cancer Society's Cancer Prevention Study II. Doctoral dissertation, Emory University, Atlanta, GA. wwwlib.umi.com/dxweb/search $=9536370$.

Enstrom, J. E., and Kabat, G. C. 2003a. Environmental tobacco smoke and tobacco related mortality in a prospective study of Californians, 1960-1998. Br. Med. J. 326:1057-1061 http://bmj.com/ cgi/reprint/326/7398/1057.pdf.

Enstrom, J. E., and Kabat, G. C. 2003b. Passive smoking: Authors' reply. Br. Med. J. 327:504-505. http://bmj.com/cgi/content/full/ $327 / 7413 / 504$.
Enstrom, J. E., and Kabat, G. C. 2004. The Lancet's call to ban smoking in the UK. Lancet 363:398-399. http://www.thelancet. com/journals/lancet/article/PIIS0140673604154469/fulltext.

Friedman, G. D., Petitti, D. B., and Bawol, R. D. 1983. Prevalence and correlates of passive smoking. Am. J. Public Health 73:401-405.

Garland, C., Barrett-Connor, E., Suarez, L., Criqui, M. H., and Wingard, D. L. 1985. Effects of passive smoking on ischemic heart disease mortality on nonsmokers: A prospective study. Am. J. Epidemiol. 121:645-650.

He, J., Vupputuri, S., Allen, K., Prerost, M. R., Hughes, J., and Whelton, P. K. 1999. Passive smoking and the risk of coronary heart disease - a meta-analysis of epidemiologic studies. $N$. Engl. J. Med. 340:920-926. http://content.nejm.org/cgi/reprint/340/ 12/920.pdf.

Howard, G., and Thun, M. J. 1999. Why is environmental tobacco smoke more strongly associated with coronary heart disease than expected? A review of potential biases and experimental data. Environ. Health Perspect. 107(suppl. 6):853-858.

Humble, C., Croft, J., Gerber, A., Casper, M., Hames, C. G., and Tyroler, H. A. 1990. Passive smoking and 20-year cardiovascular disease mortality among nonsmoking wives, Evans County, Georgia. Am. J. Public Health 80:599-601.

Jenkins, R. A., Palausky, A., Counts, R. W., Bayne, C. K., Dindal, A. B., and Guerin, M. R. 1996. Exposure to environmental tobacco smoke in sixteen cities in the United States as determined by personal breathing zone air sampling. J. Expos. Anal. Environ. Epidemiol. 6:473-502.

Jurek, A. M., Greenland, S., Macdonaldo, G., and Church, T. R. 2005. Proper interpretation of non-differential misclassification effects: Expectations vs observations. Int. J. Epidemiol. 34:680-687.

Kawachi, I., Colditz, G. A., Speizer, F. E., Manson, J. E., Stampfer, M. J., Willett, W. C., and Hennekens, C. H. 1997. A prospective study of passive smoking and coronary heart disease. Circulation 95:2374-2379.

Kluger, R. 1996. Ashes to ashes: America's hundred-year cigarette war, the public health, and the unabashed triumph of Philip Morris. New York: Alfred A. Knopf.

Law, M. R., Morris, J. K., and Wald, N. J. 1997. Environmental tobacco smoke exposure and ischaemic heart disease: an evaluation of the evidence. Br. Med. J. 315:973-980. http://bmj.com/cgi/ content/full/315/7114/973 .

Layard, M. W., 1995. Ischemic heart disease and spousal smoking in the National Mortality Followback Survey. Regul. Toxicol. Pharmacol. 21:180-183.

LeVois, M. E., and Layard, M. W. 1995. Publication bias in the environmental tobacco smoke/coronary heart disease epidemiologic literature. Regul. Toxicol. Pharmacol. 21:184-191. http://www. sciencedirect.com.

Muscat, J., and Wynder, E. 1995. Exposure to environmental tobacco smoke and the risk of heart attack. Int. J. Epidemiol. 24:715-719.

National Cancer Institute. 1999. Health effects of exposure to environmental tobacco smoke: The report of the California Environmental Protection Agency. Smoking and Tobacco Control Monograph No. 10. Bethesda, MD: U.S. Department of Health and Human Services, National Institutes of Health, National Cancer Institute. NIH Publication No. 99-4645.

Phillips, K., Howard, D. A., Browne, D., and Lewsley, M. 1994. Assessment of personal exposures to environmental tobacco smoke in British nonsmokers. Environ. Int. 20:693-712. 
Phillips, K., Howard, D. A., Bentley, M. C., and Alvan, G. 1998. Measured exposures by personal monitoring for respirable suspended particles and environmental tobacco smoke of housewives and office workers resident in Bremen, Germany. Int. Arch. Occup. Environ. Health 71:201-212.

Phillips, K., and Bentley, M. C. 2001. Seasonal assessment of environmental tobacco smoke and respirable suspended particle exposures for nonsmokers in Bremen using personal monitoring. Environ. Int. 27:69-85.

Sandler, D. P., Comstock, G. W., Helsing, K. J., and Shore, D. L. 1989a. Deaths from all causes in non-smokers who lived with smokers. Am. J. Public Health 79:163-167.

Sandler, D. P., Helsing, K. J., Comstock, G. W., and Shore, D. L. 1989 b. Factors associated with past household exposure to tobacco smoke. Am. J. Epidemiol. 129:380-387.

Smith, R. 2003. Passive smoking: Comment from the editor. Br. Med. J. 327:505. http://bmj.com/cgi/content/full/327/7413/ 505 .

Steenland, K., Thun, M., Lally, C., and Heath, C. Jr. 1996. Environmental tobacco smoke and coronary heart disease in the American Cancer Society CPS-II cohort. Circulation 94:622-628. http://circ. ahajournals.org/cgi/content/full/94/4/622.

Sterne, J. A. C., Bradburn, M. J., and Egger, M. 1995. Meta-analysis in STATA. In Systematic reviews, ed. British Medical Association, pp. 347-369. http://www.blackwellpublishing.com/medicine/ bmj/systreviews/samplechap.asp.
Svendsen, K. H., Kuller, L. H., Martin, M. J., and Ockene, J. K. 1987. Effect of passive smoking in the multiple risk factor intervention trial. Am. J. Epidemiol. 126:783-795.

Taylor, A. E., Johnson, D. C., and Kazemia, H. 1992. Environmental tobacco smoke and cardiovascular disease. Circulation; 86:1-4.

Thun, M. J. 2003. Passive smoking: Tobacco industry publishes disinformation. Br. Med. J. 327:502-503. http://bmj.com/cgi/ content/full/327/7413/502-c.

Thun, M., Henley J., and Apicella, L. 1999. Epidemiologic studies of fatal and nonfatal cardiovascular disease and ETS exposure from spousal smoking. Environ Health Perspect. 107(suppl. 6):841-846 http://ehp.niehs.nih.gov/members/1999/suppl-6/841-846thun/thunfull.html.

Ungar, S., and Bray, D. 2005. Silencing science: partisanship and the career of a publication disputing the dangers of secondhand smoke. Pub. Understand. Sci. 14:5-23 http://pus.sagepub.com/cgi/ reprint/14/1/5.

U.S. Department of Health and Human Services. 2001 Women and smoking: a report of the surgeon general-2001. pp. 343-367. Washington, DC: Government Printing Office. http://www.cdc.gov/ tobacco/sgr/sgr_forwomen/pdfs/chp3.pdf.

U.S. Environmental Protection Agency. 1992. Respiratory health effects of passive smoking: Lung cancer and other disorders. Washington, DC: Office of Research and Development, Office of Health and Environmental Assessment. EPA 600/6-90/006F and NIH Publication No. 93-3605.

Appendix Table 1

Meta-analysis formulas used to calculate a summary RR from individual RRs based on the fixed effects model (He et al., 1999; Sterne et al., 1995)

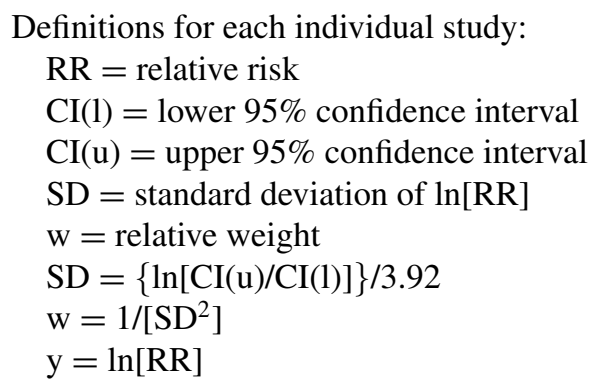

Definitions for meta-analysis combination of individual studies:

$\mathbf{R R}=$ Summary $R R=\exp [\mathbf{Y}]$, where $\mathbf{Y}=\{\mathrm{SUM}[\mathrm{w} \times \mathrm{y}]\} / \mathbf{W}$ and $\mathbf{W}=\mathrm{SUM}[\mathrm{w}]$

$\mathbf{C I}(\mathbf{I})=$ Summary $\mathrm{CI}(\mathbf{l})=\mathbf{Y} \times \exp \{-1.96 / \mathrm{sqrt}[\mathbf{W}]\}$

$\mathbf{C I}(\mathbf{u})=$ Summary CI $(\mathrm{u})=\mathbf{Y} \times \exp \{+1.96 / \mathrm{sqrt}[\mathbf{W}]\}$

Definitions for test of heterogeneity of individual RRs in summary RR:

$\mathbf{Q}=\operatorname{SUM}\left[\mathrm{w} \times(\mathrm{y}-\mathbf{Y})^{2}\right]$

$\mathbf{p}=$ CHISQ $(\mathbf{Q}$, DOF -1$)$, where CHISQ is the chi-square distribution and DOF is number of RRs compared 


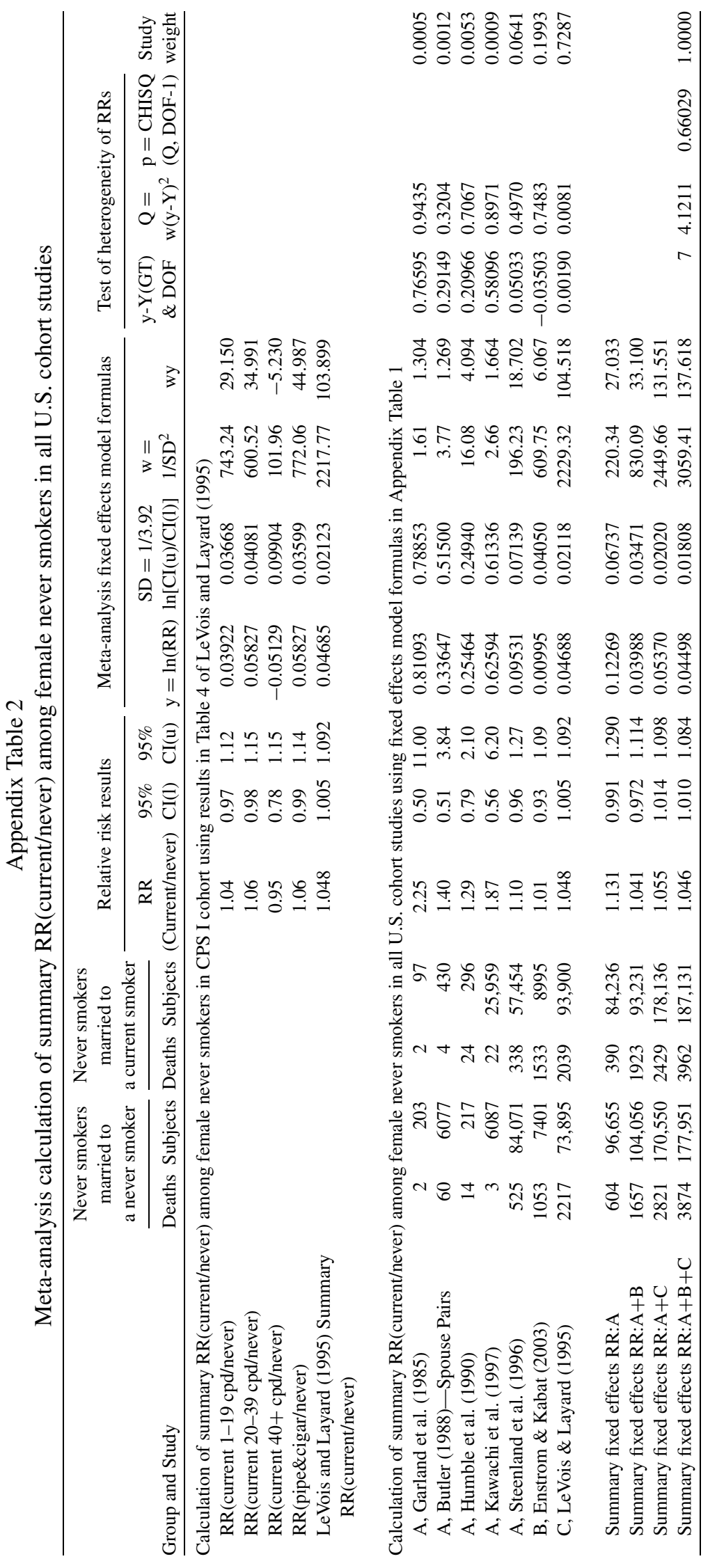

